\title{
SOME OBSERVATIONS ON THE ACTION OF CERTAIN SODIUM BILE SALTS ON THE GONOCOCCUS
}

\author{
By I. N. ORPWOOD PRICE, from the London County \\ Council (Whitechapel) Clinic Laboratory, E.I.
}

SINCE Neufold ${ }^{1}$ discovered in I9oo that bile has a bacteriolytic effect on pneumococci, many workers have investigated the action of the various bile salts on this organism. In I920 Avery and Cullen ${ }^{2}$ found that pneumococci possess a hydrolysing ferment, and later (I923) ${ }^{3}$ that this enzyme has a bacteriolytic action on dead pneumococci. The general opinion is that bile salts produce an environment for pneumococci which accelerates the action of the intracellular enzyme in the organisms, and that this results in their lysis.

As autolysis of the gonococcus is generally considered to be due to an intracellular enzyme, it was decided to ascertain whether bile salts had a similar effect on the gonococcus, and, if so, whether the resulting solution of the gonococcus could be used as an antigen for serological reactions or for immunisation purposes; also whether any evidence could be obtained that would justify the trial of these salts in the treatment of gonorrhœa.

To decide which of the large number of preparations obtainable from bile salts was most likely to succeed was not easy. Commercial sodium taurocholate was rejected because of unsatisfactory laboratory tests (I.N.O.P.), disappointing clinical results (Anwyl-Davies ${ }^{4}$ ) and Mair's ${ }^{5}$ statement (I9I7) that the use of this salt is not to be recommended. From a study of the literature on the pneumococcus, especially the excellent papers by Mair (I929), ${ }^{6}$ and Downie, Stent and White (I930), ${ }^{7}$ the most suitable salts for trial seemed to be (I) the sodium salt of cholic acid and (2) sodium deoxycholate.

The gonococci to be tested were grown on hydrocele agar $(p \mathrm{H} 7.5)$ at $37.5^{\circ} \mathrm{C}$. for twenty-four hours, washed off with saline, and two suspensions were made-(I) I,500 million to I c.c. and (2) 3,200 million to I c.c. 


\section{SODIUM BILE SALTS ON THE GONOCOCCUS}

The Action of the Sodium Salt of Cholic Acid.-When this salt (Sandoz Ltd.) was added to either strength of suspension of the organisms in any dilution of onetwentieth or more at a temperature of $22^{\circ} \mathrm{C}$., no autolysis was observed in twenty-four hours. With a dilution of one-tenth of the salt slight lysis occurred in the tube containing $I, 500$ million organisms to the cubic centimetre, but none was seen in the stronger suspension.

Further experiments with the same reagents at varying temperatures, e.g., $4^{\circ} \mathrm{C}$., $37^{\circ} \mathrm{C}$., $40^{\circ} \mathrm{C}$. and $58^{\circ} \mathrm{C}$., had the same negative results. It was concluded that the sodium salt of cholic acid had an almost negligible effect in influencing the rate of autolysis of gonococci.

The Action of Sodium Deoxycholate.-Various dilutions of the salt were added to suspensions of gonococci. The experiments were performed at room temperature, and the results in terms of autolysis are tabulated below.

\section{TABLE I}

Gonococci used in a Suspension of I,500 million per Cubic Centimetre

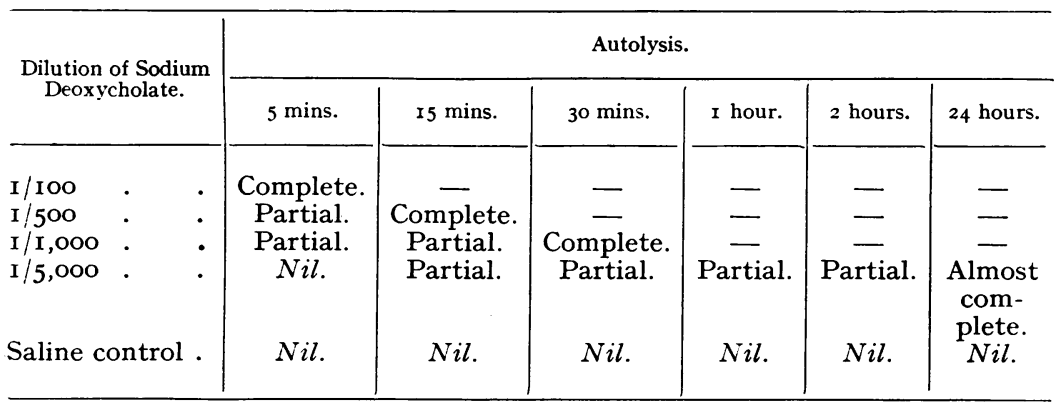

TABLE II

Gonococci used in a Suspension of 3,200 million per Cubic Centimetre

\begin{tabular}{|c|c|c|c|c|c|c|}
\hline \multirow{2}{*}{$\begin{array}{c}\text { Dilution of } \\
\text { Sodium } \\
\text { Deoxycholate. }\end{array}$} & \multicolumn{6}{|c|}{ Autolysis. } \\
\hline & 5 mins. & 15 mins. & 3o mins. & I hour. & 2 hours. & 24 hours. \\
\hline I/IOO & Complete. & - & - & - & - & - \\
\hline I/500. & Partial. & Complete. & - & - & - & - \\
\hline $\mathbf{I} / \mathbf{I}, \mathbf{0 0 0}$ & Nil. & Nil. & Partial. & Almost & Complete. & - \\
\hline $\mathrm{I} / 5,000$ & Nil. & Nil. & Nil. & Nil. & Nil. & Nil. \\
\hline Saline control & Nil. & Nil. & Nil. & Nil. & Nil. & Nil. \\
\hline
\end{tabular}




\section{BRITISH JOURNAL OF VENEREAL DISEASES}

There was no difference in the autolytic action whether the organisms were suspended in distilled water or in physiological saline.

The experiments in the tables above were performed with cultures of not more than forty-eight hours' growth. Therefore, the above figures do not assess the value of sodium deoxycholate in causing lysis if a culture older than forty-eight hours is used; the older a gonococcal culture, the quicker is its tendency to lysis. The sodium deoxycholate used (British Drug Houses) is soluble in an alkaline solution only; it precipitates out at $6.8 p \mathrm{H}$. If the reaction of the solution of autolysed gonococci is lowered towards $6.8 \mathrm{pH}$, there is a tendency to "gel." Below $6.8 p \mathrm{H}$ the salt and the protein are precipitated, and no method was discovered of separating the two. If this could be done, the protein fraction might be found to have antigenic properties.

With regard to the effect of temperature, it was found that autolysis was quicker at the higher temperatures than the lower, but the relationship between the strength of the salt used and the strength of the suspension of the organisms did not alter appreciably.

The above tables show that sodium deoxycholate has a very definite effect in promoting autolysis of the gonococcus. That this autolysis is probably due to a property of the living gonococcus is shown by the fact that, if sodium deoxycholate is added to a suspension of killed organisms in any strength as used in the above experiments, no autolysis, as far as could be ascertained, occurred. This suggests that the intra-cellular enzyme of the gonococcus is the essential factor in the autolysis of the organism and that the bile salt acts as an accessory, possibly by lowering the surface tension of the fluid medium in which the organism is suspended.

On the other hand, while sapotoxin, sodium cholate and sodium taurocholate also lower surface tension, these salts failed to produce the lytic results obtained with sodium deoxycholate.

The clear solution resulting from the action of sodium deoxycholate on a suspension of gonococci was then tested as an antigen in the complement fixation test for gonorrhœa and found to be useless, possibly owing to the salt preventing efficient fixation of the complement. An attempt was also made to use the solution as an antigen 


\section{SODIUM BILE SALTS ON THE GONOCOCCUS}

in precipitation tests on the lines of Dean's well-known work, ${ }^{8}$ but in spite of many experiments only negative results were obtained. Similarly, numerous experiments failed to demonstrate any immunising properties in the solution.

To obtain some evidence that would justify a trial of the salt in the local treatment of patients, experiments were carried out to determine the effect of sodium deoxycholate on pus from cases of acute gonorrhœal urethritis. Pus fresh from a male urethra was mixed with an equal amount of I/400 dilution of sodium deoxycholate and divided into three portions, which were incubated for five, ten and fifteen minutes respectively at $37.5^{\circ} \mathrm{C}$. Smears stained by Gram's method were examined. After incubation for five and ten minutes respectively no organisms were seen, and only the débris of a few pus cells could be identified after searching over 200 microscopic fields. After the salt had been allowed to act for fifteen minutes no organisms or pus cells were present.

Macroscopically, all these tubes after incubation contained a "ropey mucoid mass" floating in the fluid; this structureless mass represented the remains of the pus after the action of the sodium deoxycholate on it.

\section{CONCLUSIONS}

(I) Sodium deoxycholate has a very definite effect in accelerating autolysis of the gonococcus. The efficacy of this action depends on the relationship between the strength of the salt used and the number of organisms per cubic centimetre in the fluid tested. This ratio is direct, i.e., the greater the number of organisms the stronger the salt necessary to "clear" the solution.

(2) The action of the salt is an accessory one, and, to be effective, the gonococci must be living; autolysis does not occur if the salt is added to a solution of dead gonococci.

(3) The sodium salt of cholic acid, when used in any strength above I/Io dilution, has no appreciable effect in influencing autolysis of the gonococcus.

(4) From the evidence presented it would appear that sodium deoxycholate used in a suitable dilution might be a useful adjunct in the treatment of gonorrhœa. 


\section{BRITISH JOURNAL OF VENEREAL DISEASES}

\section{REFERENCES}

(I) Neufold, F.: Z. Hyg. Infekt., 34, 454, I900.

(2) Avery, O. T., and Cullen, G. E.: J. Exp. Med., 32, 547, 1920.

(3) Avery, O. T., and Cullen, G. E. : J. Exp. Med., 38, r99, I923.

(4) Anwyl-Davies, T.: "Personal Communication: Clinical Trials Thirteen Years Ago."

(5) MaIR, W. : Biochem. J., II, II, I9I7.

(6) MAIR, W. : System of Bact. M.R.C., 2, I68, I929.

(7) Downie, A. W., Stent, L., White, S. M. : Brit. J. Exp. Path.

(8) DeAN, H. R. : System of Bact. M.R.C., 6, 426, I93I. 